\title{
Engaging Students with Research Through a Connected Curriculum: An Innovative Institutional Approach
}

\begin{abstract}
Is it possible to create an accessible, yet stimulating, conceptual framework for engaging undergraduate students in research-based programs of study? Can such a framework guide faculty as they deliver their programs and set faculty free to innovate and cross old disciplinary boundaries? Can it stimulate partnerships with students and promote dialogue about "good" education? University College London (UCL), a multidisciplinary, research-intensive university, has adopted a values-based framework designed to engage undergraduates much more closely with research. This article introduces the UCL framework, outlines its philosophical underpinnings, and discusses the ways in which adopting a shared set of principles is not only enhancing students' education within their programs of study but also providing new opportunities for them to engage with researchers, with one another, and with external communities.
\end{abstract}

Keywords: Bildung, curriculum, research-based education, student inquiry

\section{Introduction}

What should be the key characteristics of a student's journey through her or his time at a university? The authors of the report by the Boyer Commission on Educating Undergraduates in the Research University (1998) argued that "Everyone at a university should be a discoverer, a learner. That shared mission binds together all that happens on a campus. The teaching responsibility of the university is to make all its students participants in the mission" (Boyer Commission 1998, 9).

Since the publication of that report, many scholars and higher education institutions have evaluated the benefits and practical challenges of involving undergraduate students actively in research and enquiry. A number of studies have shown both the challenges and advantages of adopting a "research-based" model for undergraduate courses (Brew 2006; Lucas et al. 2008; Healey and Jenkins 2009). Some undergraduates may initially find the uncertainty of research and inquiry demanding and even unsettling. However, the benefits of engaging students in research-based activities are multiple: Students develop their critical intellect, increase their ability to solve complex problems, and develop a wide range of transferable skills (Walkington 2015). In addition, they grow in confidence as they approach the demanding complexities of knowing and acting in the modern world (Fung forthcoming).
University College London (UCL) in the United Kingdom has published a 20-year institutional strategy, UCL 2034 (UCL 2014a), which aims to bring its research mission and students' education closer in order to be a force for good in the world. Professor Michael Arthur (2014), UCL's president and provost, led the development of the strategy, which provides a values-based commitment to an enhanced global impact. The process resulted in the university's adoption of a Connected Curriculum framework (Fung 2015; Fung forthcoming), which serves as a guide for faculty discussions and decision-making in the design and development of programs of study. The framework is helping to shape conversations in departments and across the institution about the wider student experience at UCL. The framework also is enabling academic faculty to engage students more fully, not only through active rather than passive learning (Evans et al. 2015) but also through developing opportunities for partnership with students (Healey et al. 2014) as we look toward the future as a learning and research community. This article presents the framework and its theoretical framing, examples of changing practices at UCL due to the Connected Curriculum, and examples of how we are researching and evaluating its impact.

\section{The Connected Curriculum Framework}

The Connected Curriculum framework is a simple representation of six connected dimensions of activity, all of which link to the core focus: enabling students to learn through active participation in research and inquiry (see Figure 1).

Each of the six dimensions of the framework highlights ways of thinking about conceptual and human connectivity, raising a number of questions for faculty to discuss.

Dimension 1: Students connect with researchers and with the institution's research. Are students introduced to and inspired by the latest research in the field, including that undertaken by members of the department? Do their courses and the wider activities and events in their department enable them to meet, learn from, and even challenge researchers and scholars? Where appropriate, do students also engage with professionals who undertake critical inquiry into practice?

Dimension 2: A "throughline" of research activity is built into each program of study. Is there a connective story line of inquiry-for example, in the pattern of learning/research activities and assessments-that helps students to build their own coherent learning narrative throughout the whole program 
Figure 1. The Connected Curriculum Framework (Fung 2015)

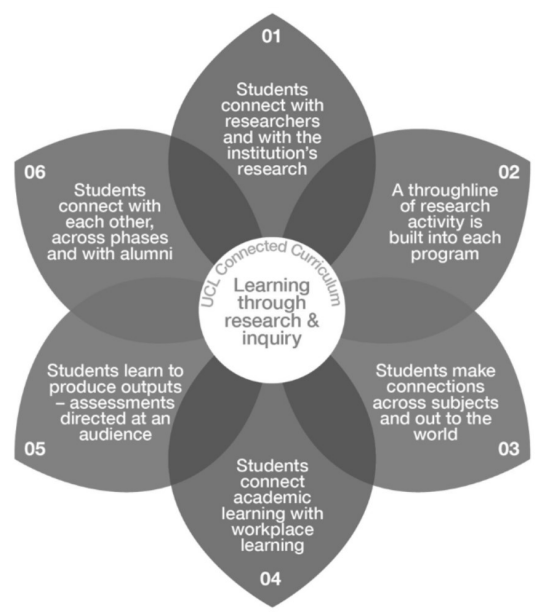

of study? Is there a clearly constructed sequence of inquiry-based activities across years of study that enable students to go beyond accumulating knowledge and develop themselves reflectively as whole, critical, creative persons?

Dimension 3: Students make connections across subjects and out to the world. Can students connect beyond their immediate subject(s) of study and learn to analyze and tackle multilayered challenges using different "knowledge lenses"? In doing this, can they build understandings of and links with appropriate external communities and organizations? Are they encouraged to analyze their ethical bearings through developing research integrity, social responsibility, and global citizenship?

Dimension 4: Students connect academic learning with workplace learning. Are students developing a range of professional attributes, such as leadership, creativity, project management, communication, and problem-solving skills? Can they make and articulate conceptual, practical, and values-related connections between their academic learning and the lifelong learning needed for employment and for their future lives?

Dimension 5: Students learn to produce outputs-assessments directed at an audience. Are some assessments of student learning directed outward, at an identified audience, giving students a voice beyond the class? Can students demonstrate an ability to use a range of digital media effectively, as well as different modes of writing, visual communication, and oral communication, as they express their insights and arguments to others within and beyond the institution?

Dimension 6: Students connect with each other, across phases and with alumni. Are students explicitly invited into an inclusive research and learning community? Are there opportunities for them to meet, mentor, and work collaboratively with their fellow students across different academic years? Are alumni actively engaged in the learning and research com- munity, for example by enriching the curriculum with their expertise, contributing to mentoring programs, or working with departments to enhance the design and content of their courses?

These dimensions all draw on aspects of inquiry-based pedagogy explored in the literature (see Brew 2006; Healey and Jenkins 2009; Lucas et al. 2008; Walkington 2015). However, our new framework brings together into one whole, for faculty and students, two key elements: a pedagogical emphasis on learning through active inquiry and a values-based emphasis on building inclusive communities (see Walkington $2015,13)$.

Although most UCL departments have included research in their undergraduate curricula for many years, the connected framework is promoting rich discussions at UCL about ways in which research-based education can be enhanced. Program teams are discussing existing programs of study and considering how they can be further developed. The framework is also a means of shaping dialogue between faculty in different subject areas on questions such as how they might develop more explicit connections between, say, literature and politics or between physics and architecture? Most important, the framework is promoting active engagement with students and student representatives not only at the program level but also at the level of their school or faculty and at institutional level. Such engagement reflects the principles of the curriculum, which foregrounds the values as well as the practices of dialogue with others, seeing productive human relationships not only as the means to education but also its goal (Biesta 2006; Fung forthcoming; UNESCO 2015).

\section{Philosophical Underpinnings}

The Connected Curriculum framework draws on the European tradition of Bildung, a German term defined by twentieth-century philosopher Hans-Georg Gadamer as "the properly human way of developing one's natural talents and capacities" (Gadamer 2004, 9). Such development is achieved through engagement with others' perspectives and knowledge horizons. "Good" education here is about enabling students to develop themselves, both individually and in communities, through dialogue and through active, critical engagement within and across subject fields.

In this tradition, education enables us to question existing fields of knowledge, to understand where the edges of those fields of knowledge lie. It helps individuals and communities to develop what it is possible to know. Gadamer (2004) emphasizes the importance of developing a frame of mind in which we are able to distance ourselves from what immediately appears to be true. As Fairfield puts it, the human mind needs to be "unsatisfied with what it imagines it knows" (Fairfield 2012, 3). This moves beyond the notion of learning as simply acquiring knowledge and skills and toward emphasizing the explicit development of a willingness to be open 
to alternative possibilities. Education is about acquiring not just information but also "a concern for the 'common good" (Gadamer 2004, 29). As Reindal has argued, Bildung is about "being responsible in relation to oneself as a human being" (Reindal 2013, 537).

Good education, according to this framing, focuses on the development of a human disposition that allows our personal horizons to change and expand through interacting and collaborating with others. Both student researchers and researcher-educators develop new understandings together, looking outward to the challenges and opportunities provided by our communities and wider society.

The UCL Connected Curriculum framework reflects this philosophy. Its core aim is to use critical inquiry to promote values-based dialogue and the development of inclusive communities. Thus it has a collectivist rather than an individualist focus. We define the term curriculum broadly, using it to include not only planned teaching and learning activities and curricular content but also the students' lived experiences of learning while they study with us. We draw here on William Pinar's theoretical framing (Pinar 2012), which represents curriculum not as narrowly formulated objectives and standardized testing but as "complicated conversation, as communication informed by academic knowledge" (Pinar 2012 , 19). The curriculum is seen as a means of enabling students and teachers to develop and express their own identities so that "scholarship can enable them to speak" (Pinar 2012, 22).

These themes have strong connections with research as well as with education. Although research has distinctive characteristics in different fields of inquiry, all researchers are, by definition, "re-searching"-looking again and seeking new knowledge, explanations, and understandings. Investigating evidence, argument, and practice through dialogue, collaboration, and peer review, researchers must then communicate their findings. Through engaging with research and inquiry, students can also become "producers" (Neary 2014) and learn to present their ideas to the world. In a research-intensive institution, there are opportunities for students to link readily to cutting-edge research. However, the core principles of our framework can be applied to any educational institution. Teachers and students alike can model a disposition for critical inquiry, forge connections across traditional subject boundaries, connect with one another, and use developing knowledge to make an impact on local and wider communities.

So what evidence is there at UCL that the introduction of this framework is contributing to the realization of these values? Are opportunities for student inquiry, engagement, and development of their personal "voice" growing? This longterm initiative is in its early years, and there is much research to do into its effects, but we are already seeing benefits on three levels: programs of study, departments and faculties, and the institution as a whole.

\section{Programs of Study}

The framework has enabled UCL departments, including faculty members and student representatives, to build on existing research-based learning activities and to share local effective practices with others across the institution. Through an institutional website, the UCL Teaching and Learning Portal (UCL 2015a), inspirational case studies are being showcased under the heading "Curriculum Inspirations."

One example is from the history department, which has introduced a Making History module (UCL 2015b) for firstyear undergraduates. The module challenges them to think laterally and creatively about the historical resources all around them in the historic city of London. Through collaborative inquiry, students analyze a significant historical question, using primary as well as secondary historical sources. Working in teams, they investigate a rich range of London-based archives, documents, objects, collections, buildings and landmarks, images, and sounds. The groups present their research activities and findings online-for example, by making short videos for a public audience.

Another case study comes from engineering, where regular classes are suspended for a week so that second-year undergraduates can work in mixed groups to build articles of "smart" clothing (UCL 2015c). Their brief is to design and build an item of clothing to monitor a marathon runner's well-being, provide alerts to the runner, and prevent injury. Students are encouraged to be creative in researching and developing their own solutions to the design. Provided with a range of components, including temperature and pressure sensors, accelerometers, and conductive rubber, students have only $£ 40$ (approximately US\$52) available for materials, so they have to manage the budget carefully, besides completing their projects on time.

In a zoology module, Mystery Specimen (UCL 2015d), students are each given a different part of an animal and asked to identify it, then write a journal article about their experiences. Engaging in close anatomical observation and making reference to museum collections, students develop their "diagnosis" systematically, writing it up in the style of an article for a given research journal.

Even in departments that already have a strong track record of providing research-based education, faculty members are seeking ways of enhancing practice. Olga Thomas, vice-dean of education in the UCL Faculty of Laws, shares with colleagues the design of successful research-based modules, including one called Access to Justice and Community Engagement in which students "engage with academic scholarship and research while undertaking practical casework [and] taking on a real client from the community" (UCL 2015d).

She explains that the faculty has been inspired by the Connected Curriculum framework to innovate further, ex- 
ploring "a connected 'throughline' of research and the diversification of assessment methods to include some form of research 'outputs' in its next curriculum review." The faculty also is exploring ways to assess work done by groups of students as a way to meet the dimension of the connected framework that seeks to promote "students connecting closely with one another" (UCL 2015d).

These program-level examples illustrate how the curricular framework is being used to promote the development of new, authentic research-based approaches to learning and teaching across UCL. Students' responses to the developments have been very positive, and program teams continue to build on student and faculty evaluations and ideas to make further enhancements.

\section{Effects on Departments and Schools}

The Connected Curriculum initiative also addresses departmental cultures beyond specific programs of study. Multidisciplinary faculties are using the framework as a catalyst for engaging students more directly with the research being undertaken by scholars. One example is the UCL Faculty of Brain Sciences, which drew on a resource developed as part of the curriculum initiative (UCL 2015f) to introduce a collaborative activity called "Meet the Researcher."

The Faculty of Brain Sciences, which offers three large undergraduate degree programs, has a very strong research profile in psychology, psychiatry, and neuroscience and also has more than $800 \mathrm{PhD}$ students. The introduction of the Meet the Researcher activity for new undergraduates had four specific aims:

1. To improve [the] transition from secondary education and help students get to know one another and develop teamwork skills;

2. To develop key transferable skills [in students such as] project management; distilling and synthesizing key ideas; [and] interviewing and peer reviewing;

3. To develop [students'] communication skills, including their ability to select appropriate language for a specified audience; [and]

4. To introduce students to the wider research culture of the [f]aculty and to the work of one research-active academic in particular. (Standen and Evans 2015)

In groups of five or six, the students have a week to decide which researchers they want to meet. They are given a time and location for the informal interview and are encouraged to ask researchers genuine and demanding questions about their work-about the values and intentions behind it, as well as the practices and outcomes. The students then prepare and deliver group presentations on the work of "their" researcher. Presentations are not formally assessed, but groups receive feedback from peers and tutors.
Student reviews of the activity via surveys have been excellent, with well over 90 percent of the student participants stating that the experience was very positive, and many agreed that the activity had helped them better understand UCL's research community (Standen and Evans 2015). Tutors and researchers have also responded extremely positively. Tutors themselves feel more connected with the wider research community, and specialist researchers enjoy working with keen students. A faculty member from brain sciences is now promoting the Meet the Researcher activity across UCL, working with a number of departments to implement it more widely.

\section{Results at the Institutional Level}

As well as stimulating activity at the program and faculty levels, the Connected Curriculum has inspired a number of cross-institutional initiatives that enable students to collaborate with faculty to bring about educational change. Especially promising is UCL ChangeMakers, an initiative directed at enabling students to propose and lead research projects focused on enhancing education. (UCL 2015g). Following a pilot year in which 10 groups of student volunteers proposed and led projects of importance to them, the activity has grown rapidly, with more than fifty student-led and staff-led projects being funded by the UCL Centre for Advancing Learning and Teaching during 2015-2016. Criteria for funding include having a clear strategy for working in partnership with students to address one or more of the Connected Curriculum dimensions.

In an evaluation of students' experiences working as UCL ChangeMakers, students expressed "amazement" that they were "given time, funding and support to develop their projects." They talked of how they felt "more empowered, less passive" and recognized that they had become co-constructors in their own education (UCL 2015h). Students from across the institution now are being recruited annually as UCL ChangeMaker Scholars. They are becoming experts in the aims of our new curricular framework, particularly student assessment and feedback, and they are working creatively with departments to explore opportunities for developing practice in these areas.

Institution-wide working groups have been set up so that students, faculty members, and professional staff can work together to address specific themes, such as enterprise or personal tutoring. One group on "Liberating the Curriculum" is exploring ways of ensuring that the curriculum explicitly includes and respects the scholarship, publications, and perspectives of those who have traditionally been marginalized, including women and minority ethnic groups and individuals. The working groups report to a curriculum-development group, in which students and faculty "fellows" assigned to the initiative one day a week work toward shared goals. The underlying principle throughout is advancement through dialogue, of giving a voice to all in our diverse learning and research community. 


\section{Early Conclusions, Challenges, and Opportunities}

So is the introduction of the Connected Curriculum framework at UCL having the desired effects? Although it is still in its early years, it has undoubtedly begun to create opportunities for engaged dialogue among and across groups of students and faculty. It is opening up more connections between students and the outside world, through increasing the number of assessments of students' learning that look beyond the classroom. At the faculty level, initiatives such as Meet the Researcher have received extremely positive feedback from both students and faculty and are helping to create stronger local communities of learning and research. And at the institutional level, students are initiating and engaging in educational change projects, developing leadership and research acumen while advancing educational goals.

In addition, there is a renewed emphasis on enriching the skills and knowledge of faculty members in relation to research-based education (Jenkins and Healey 2015). Through a program called UCL Arena, faculty are able to share their innovative practices and related scholarship by running "exchange seminars" for colleagues, and they can even gain nationally recognized "professional recognition" fellowships for their involvement (UCL 2015e).

Undertaking cross-institutional change is no simple task, however. UCL has a long tradition of giving faculty members the freedom to decide how they design and deliver programs of study, and although the Connected Curriculum keeps the decision-making very much in the hands of faculty and departments, some are cautious about any institutional initiative that characterizes a particular approach to education as having value for the whole institution. One lecturer commented in a small-scale 2015 survey that there remain "fundamental cultural challenges" to implementing a research-based education model, however flexibly framed.

The institution's leaders thus are keen to ensure that instead of requiring what Barnett and Coate describe as "performative professionalism" among faculty-a trend sometimes linked with institutional-change initiatives-they promote "a reflexive, collective, developmental and process-oriented model" (Barnett and Coate, 2005, 18). Moreover, the curriculum framework is prompting discussion of ways to promote academic freedom not only for faculty but also for students, so that they can fully develop their capabilities through "a curriculum that places an emphasis on the development of students as independent, critical thinkers" (Macfarlane 2012, 730).

Many faculty members have highlighted the vital importance of ensuring that reward systems are changed to motivate faculty to commit time and energy to developing their approaches to teaching and learning, as the Boyer Commission (1998) advised. At present in the United Kingdom, most reward and prestige in research-intensive institutions grows from developing an international research profile, although this is beginning to change (Fung and Gordon 2016).
Addressing such embedded cultural practices will take time, and arguably one of the strengths of the current initiative is its long-term timeframe, and the degree to which staff and students are working collaboratively to find creative ways forward.

We will continue to review, research, and evaluate the initiative in the coming years, in line with the goals of the UCL 2034 strategy. We are undertaking a number of related research projects, including focus groups for students and for faculty, as well as analyses of the online and physical learning spaces needed for research-based education. An important cross-institutional element is the development of a curricular benchmarking guide, which presents four benchmark descriptors for each of the six Connected Curriculum dimensions-characterizing each dimension as beginning, developing, developed, and outstanding. It is planned that during 2016-2017, which will be the first year of the new "UCL Education Strategy 2016-2021" (UCL 2015i), every program of study will evaluate itself against this guide. Faculty and professional staff will work in partnership with students to do this, and the exercise will be repeated after two and four years. The aim is that this evaluation at the program level, supported by qualitative, narrative commentaries highlighting progress and future objectives, will be peer reviewed as part of the existing periodic departmental review process. The full spectrum of studies and evaluations will inform an overarching narrative of institutional change; this in turn will be juxtaposed with comparable change narratives from key international partners to form a broader study.

Early indications are that our Connected Curriculum framework is effectively promoting ways of engaging students more closely with research, with faculty members, and with one another. There is still much to do, but if students are able to articulate their developing dispositions for critical, collaborative inquiry, demonstrate a rich spectrum of skills and attributes, and speak out confidently as active partners and leaders within and beyond the university community, we will be fulfilling our goals.

\section{References}

Arthur, Michael. 2014. "From Research-led to Research-based Teaching." Research Fortnight, April 30. Accessed December 28, 2015. http://www. researchresearch.com/index.php?option=com_news\&template=rr_2col\&view=article\&articleId=1343435

Barnett, Ronald, and Kelly Coate. 2005. Engaging the Curriculum in Higher Education. Maidenhead, UK: Society for Research into Higher Education/ Open University Press.

Biesta, Gert J. J. 2006. Beyond Learning: Democratic Education for a Human Future. Boulder, CO: Paradigm. doi: 10.4324/9781315635811

Boyer Commission on Educating Undergraduates in the Research University. 1998. Reinventing Undergraduate Education: A Blueprint for America's Research Universities. Stony Brook, NY: State University of New York at Stony Brook for the Carnegie Foundation for the Advancement of Teaching. Accessed 


\section{(CUR uarterly}

December 15, 2015. https://www.adelaide.edu.au/rsd/evidence/related-articles/Boyer_Report.pdf

Brew, Angela. 2006. Research and Teaching: Beyond the Divide. London: Palgrave Macmillan.

Evans, Carol, Daniel Muijs, and Michael Tomlinson. 2015. Engaged Student Learning: High-Impact Strategies to Enhance Student Achievement. York, UK: Higher Education Academy. Accessed December 27, 2015. https://www. heacademy.ac.uk/sites/default/files/engaged_student_learning_high-impact_ pedagogies.pdf

Fairfield, Paul. (Ed.). 2012. Education, Dialogue and Hermeneutics. London: Continuum. doi: 10.5040/9781472541123.

Fung, Dilly. 2015. UCL Connected Curriculum: A Distinctive Approach to Research-based Education. London: University College London Centre for Advancing Learning and Teaching. Accessed December 3, 2015. http:// www.ucl.ac.uk/teaching-learning/connected-curriculum/CC_Brochure_for_ online_viewing_.pdf

Fung, Dilly. Forthcoming. A Connected Curriculum for Higher Education. London: UCL Press.

Fung, Dilly, and Claire Gordon. 2016. Rewarding Educators and Education Leaders in Research-Intensive Universities. York, UK: HE Academy. Accessed July 27, 2016. https://www.heacademy.ac.uk/sites/default/files/rewarding_educators_and_education_leaders.pdf

Gadamer, Hans-Georg. 2004. Truth and Method. 2nd rev. ed. Translated by J. W. Marshall. London: Continuum.

Healey, Mick, Abbi Flint, and Kathy Harrington. 2014. Engagement through Partnership: Students as Partners in Learning and Teaching in Higher Education. York, UK: HE Academy.

Healey, Mick, and Alan Jenkins. 2009. Developing Undergraduate Research and Inquiry. June. York, UK: Higher Education Academy. Accessed December 27, 2015. https://www.heacademy.ac.uk/sites/default/files/developingundergraduate_final.pdf

Jenkins, Alan, and Mick Healey. 2015. "International Perspectives on Strategies to Support Faculty Who Teach Students via Research and Inquiry." CUR Quarterly 35(4): 31-37.

Lucas, Lisa, Mick Healey, Alan Jenkins, and Chris Short. 2008. Academics' Experiences and Perceptions of "Research" and "Teaching": Developing the Relationship between These Activities to Enhance Student Learning within Different Disciplines and Institutions. York, UK: Higher Education Academy. Accessed December 1, 2015. https://www.heacademy.ac.uk/sites/default/files/ lucas_final_report_1.pdf

Macfarlane, Bruce. 2012. "Re-framing Student Academic Freedom: A Capability Perspective." Higher Education 63: 719-732. doi: 10.1007/s10734011-9473-4

Neary, Mike. 2014. "From the International Desk: Student as Producer: Research-engaged Teaching Frames University Wide Curriculum Development." CUR Quarterly 35(2): 28-34.

Pinar, William F. 2012. What Is Curriculum Theory? New York: Routledge.

Reindal, Solveig M. 2013. "Bildung, the Bologna Process and Kierkegaard's Concept of Subjective Thinking." Studies in Philosophy and Education 32: 533-549. doi: 10.1007/s11217-012-9344-1

Standen, Alex, and Julie Evans. 2015. "Meet the Researcher: Connecting Students and Researchers from Day One." Peer-reviewed paper, UK Society for Research into Higher Education Annual Conference, Newport, South Wales, United Kingdom, December. https://www.srhe.ac.uk/conference2015/ downloads/SRHE_NR_Abstracts_2015_v2.pdf
University College London (UCL). 2014a. UCL 2034: A New 20-year Strategy for UCL. Accessed December 3, 2015. https://www.ucl.ac.uk/ucl-2034

UCL. 2014b. "Mystery Specimen" Project. Accessed December 28, 2015. https://www.ucl.ac.uk/teaching-learning/case-studies-news/object-basedlearning/mystery-specimen

UCL. 2015a. UCL Teaching and Learning Portal. Accessed December 3, 2015. https://www.ucl.ac.uk/teaching-learning/

UCL. 2015b. Enhancing First-year Undergraduates' Expertise and Skills through Group Research [Making History Undergraduate Module]. Accessed December 28, 2015. https://www.ucl.ac.uk/teaching-learning/case-studiesnews/keyskills-ppd/first-year-research-project

UCL. 2015c. Engineering Case Study: Second Year Students Problem-solving through Scenarios. Accessed December 28, 2015. https://www.ucl.ac.uk/ teaching-learning/case-studies-news/peer-assisted-learning/second-year-problem-solving-scenarios

UCL. 2015d. A Research-based Education in the UCL Faculty of Laws. Accessed December 28, 2015. https://www.ucl.ac.uk/teaching-learning/casestudies-news/connected-curriculum/research-based-education-laws

UCL. 2015e. UCL Arena. Accessed December 28, 2015. https://www.ucl ac.uk/teaching-learning/arena

UCL. 2015f. "Meet Your Researcher" Resource. UCL Centre for Advancing Learning and Teaching. Accessed December 28, 2015. https://www.ucl.ac.uk/ teaching-learning/connected-curriculum/Meet_your_researcher

UCL. 2015g. UCL ChangeMakers. Accessed December 28, 2015. https://www. ucl.ac.uk/changemakers

UCL. 2015h. Q\&A with the UCL ChangeMakers Team, August 2015. Accessed December 28, 2015. http://www.ucl.ac.uk/teaching-learning/ tl-news/changemakers-interview

UCL. 2015i. The UCL Education Strategy 2016-21. Accessed December 28, 2015. https://www.ucl.ac.uk/teaching-learning/2016-21

UNESCO. 2015. Rethinking Education: Towards a Global Common Good? Paris: United Nations Educational, Scientific and Cultural Organization.

Walkington, Helen. 2015. Students and Researchers: Supporting Undergraduate Research in the Disciplines in Higher Education. York, UK: HE Academy.

\section{Dilly Fung}

\section{University College London, d.fung@ucl.ac.uk}

Dilly Fung is professor of higher-education development and academic director of the Centre for Advancing Learning and Teaching at University College London (UCL). She is leading a series of initiatives designed to advance research-based education at UCL, including the innovative Connected Curriculum project, which aims to bring research and education closer together for students and faculty. Drawing on her interdisciplinary roots in literary studies, politics, and the philosophy of education, she studies how the synergies among research, education, and scholarship can be employed to bring about positive change in the world. She also investigates how academic educational leadership can be defined and rewarded in research-intensive universities.

\section{doi: $10.18833 /$ curq $/ 37 / 2 / 4$}

